\title{
Digital NarRatives: A STUdy Of The ArCAde FIRE INTERACTIVE MUSIC VIDEOS
}

\author{
Elisa Maria Rodrigues Barboza
}

\begin{abstract}
Initially seen as an audiovisual product made mainly for television, the music video, in recent years, has been expanding itself and gaining strength in the virtual environment. The possibility of easy and quick access through websites such as Vimeo and YouTube, besides the greater freedom these sites offer in comparison to the schedules of television channels, was only the beginning of the process of this format's creative development. Its embracing of the technological changes culminates with the appearance of interactive music videos that strengthen investments made in experiences of digital narratives. In this context, one of the bands that stands out is Arcade Fire, whose trajectory already counts with four interactive audiovisual projects, namely Neon Bible (Vincent Morisset, 2007), Sprawl II (Vincent Morisset, 2010), The Wilderness Dowtown (Chris Milk, 2010) and Just a Reflektor (Vincent Morisset, 2013).
\end{abstract}

\section{KeYWORDS}

Music video; digital narratives; interactivity; Arcade Fire

\section{Definition of Music Video}

In order to define the term "interactive music video", it is necessary to first understand the origin and the language of the music video as known in its initial versions, prior to its insertion in the internet. For Soares (2012: 32): "In principle, the video clip was simply called musical number. Then it would be named promo, a direct allusion to the word 'promotional'. The term video clip would finally be used only from the 8os on. "The author also mentions that the very nomenclature of this format already says a lot about its features. For him, the concept of the clip', which comes from "clipping" (for media vehicles), and tweezers or clip, relates to how its quick assembly and compact structure are conceived. Nevertheless, these qualities of the music video still focus on its commercial character, so that the images and their combination with the songs should work as an extension of the presence of the band or singers in order to promote the dissemination of their work. Recurring characteristics used to define the music video are quick cuts (often falling within the rhythm of the song), discontinuity, the presence of the band or singer performing, fragmentation, recurring use of editing effects, among others. However, due to a lack of specificity in its language (I shall further discuss this aspect), it is possible to perceive the impossibility of reaching a consensus on a definition for the production of music videos as a whole. In short, all the settings of this format are based on general trends assumed by the music video from its earliest versions.

\footnotetext{
'In Brazil, music video is mainly named as "videoclipe", so the word "clip" comes from this nomenclature.
} 
An initial point for discussion is the origin of music videos. The desire to associate image and music comes from before the consolidation of the traditional format of the music video as propagated mainly by the North American MTV from the 1980s on (and the Brazilian MTV, from the 1990s). From the Color Organ, developed by Luis Bertran Castel in France in the year 1734, which would produce colorful lights when a musical note was struck (based on the color theory developed by Newton), and other later versions to the artists of the early twentieth century such as Morgan Russell, MacdonaldWright and Wassily Kandinsky who sought, through their paintings, to represent the rhythm and movement through spaces and colors in their paintings, there is the desire to associate image and sound. In the field of moving image, in the 20 , some film artists, including Hans Richter (Rhythmus 21, 1921), Viking Eggeling (Symphonie Diagonal, 1924) and Walter Ruttmann (Lichtspiel: Opus I, 1921), sought through their film painting techniques to give the impression of the existence of a song through shapes and movement. Perhaps due to the recurring construction of a visual relationship with music, the music video, widespread mainly by MTV (initially), has such uncertain origins.

Following Shore (1985), a BBC-TV program tracing the history of promotional videos once cited a short film made in 1934 as an antecedent of the form. Journalists writing about the subject routinely mention the promotional jazz film clips made in 1940s, sometimes referred by their brand name of Soundies, and the Scopitone jukebox developed in France in the 1960s. other sources cited ate the various 1950 s movies about youth culture and rock and roll that contain sequences not unlike today's promos. On television, in the 1960s, there was The Monkees TV series, and other televisual pop, such as The Archies and The Partridge Family is often mentioned. The Beatles are often introduced into the debate as critics cite the early Beatles films (A Hard Day's Night, Help!), later promotional film clips ("Penny Lane", "Strawberry Fields Forever"), and the Magical Mystery TV special. But the most popular candidate for the title of "first" music is the Jon Roseman/Bruce Gowers six-minuties clip for Queen's number-one hit record "Bohemian Rhapsody", made in 1975 (Goodwin, 1992: 29).

As noted in the quote from Goodwin, although there is some speculation about the starting point of music videos, it is not possible to specifically state what are its exact origins in the history of audiovisual arts. Indications of these origins refer to the $1920 \mathrm{~s}$ with the historical avant-garde movement and their insinuations of the relationship between sound and image, as in the film The Jazz Singer (Alan Crosland, 1927), the first film with separately recorded and synchronized audio, that is, a musical film that would inaugurate sound film. Still during the decades of 1920 and 30 we can pinpoint the "videotaped numbers" of prominent jazz artists such as Duke Ellington and Woody Herman. It was from 1949 on that music would gain significance on TV through Paul Whiteman's Teen Club program, broadcast by North American network ABC. In the movies, one can also search for the origins of music videos in the 50s, with Elvis Presley and his first film, 
Love me tender (Clint Reno, 1956). Presley starred in a long list of movies that opened "new fronts in musical dissemination, especially with the performance of a singer in the cinema, in films whose narratives - with rare exceptions - included musical numbers" (Lima, 2011: 37). On the other hand, in the 1940s Walt Disney studios released Fantasia (Ferguson, 1940), which puts animation in a strong relation to a kinesthetic track. In a different stream, Broadway also reached movie screens with its musicals, which although initially produced for theater, were seen around the world, such as The Sound of Music (Robert Wise, 1965) and Singin 'in, the Rain (Doney Stalen, 1952), the latter becoming a central reference of its kind.

Returning to the quote from Goodwin, another pioneer phenomenon in musicals concerning Rock and the younger generations were the Beatles who, inspired by the success of Elvis's films, released A Hard Day's Night (Richard Lester, 1964), a film that mixes music and documentary and has also become an important reference for tracing the origin of music videos as we know it. Besides music itself, these musical films, both in the case of Elvis and the Beatles, had a commercial character, since they were intended to broaden the coverage and visibility of an artist's work by their audience; it was a way to satisfy the fans who could not follow the band in person. Reinforcing this commercial character, Lima (2011: 37) citing Frith shows us that RCA, Elvis's record label, intentionally created the image of a romantic, good-hearted idol who was not aggressive, as a counterpart to the trend of bands with an anarchic profile at the time. The fact that the Beatles, both in A Hard Day's Night (Richard Lester, 1964) and in Help (1965) hired Richard Lester, who was a director of television advertisement films, gave a different aspect to the final material of the movies, and also demonstrated the band's concern to produce a piece that could work as a form of commercial release.

On the other hand and in another direction, Nam June Paik, a member of Fluxus, inspired by the movie A hard day's night, created the video Beatles Eletroniques (1966) two years later. Certainly, Paik's desire was to comment and establish critical relationships with the world of media culture at the time. Using video synthesizers, Paik electronically distorted and manipulated the sound and image of the Beatles's musical documentary in a radical way. Paik's use of this reference demonstrates the importance of the original film, not only for the development of the music video into its current format, but also for the numerous developments in the field of audiovisual and pop culture imagery. Generally, the productions of Paik and Fluxus were guided by the development of an art connected to communication circuits which emerged with great intensity at that moment. Not only Fluxus reflected and still reflects on what the music video is today, but video art, in general, has been of great importance to the process of constructing the music video format especially in regard to the possibilities it created in the motion image environment. For Machado,

(...) The music video appears as one of the few spaces decidedly open for inventive minds, still capable of continuing or allowing new consequences to experimental attitudes inaugurated with the avant-garde cinema of the 
20s, the experimental cinema of the 50s-60s and video art of the 6os-70s

(Machado, 2000: 173, freely translated).

Specifically regarding the influence of video art in the music video, its heritage is especially in the handling of electronic image and in the possibilities of creating an aesthetic that had not yet appeared in cinema in a predominant way, aside from the liberty from the dominant structure of classical cinema (beginning, middle and end). Undoubtedly, the historical context of the 50 s and 6os of last century also creates a fertile environment which contributes for the origins of the music video.

In the catalog of the exhibition named "This is not a love song: Cruce de Caminos y videocreación between pop music", which took place in Barcelona, Cuevas (2013) gives an account of a moment which also demonstrates this confluence between art and commercial media in music:

Throughout their carreer as a band, The Beatles developed a strong association with the visual arts, both socially and through their work. Contrary to what is generally believed, however, it was McCartney, not Lennon, who introduced the group into London's avant garde circles. His friend, the art dealer and gallery owner Robert Fraser, made his acquaintance with artists Peter Blake and Richard Hamilton, who later created the covers for Sgt. Pepper's Lonely Hearts Club Band (1967) and The White álbum (1968), respectively. At that time, it was looked upon as entirely unprecedented that a famous artist like Peter Blake shoud work for the world's number-one pop group (Cuevas, 2013: 49).

There is, then, the undeniable existence of a flow between the artistic and commercial movements which cross the universe of music videos from its first steps to its current moment, as is the case of R.E.M., a group which released a music video in their virtual channel for each of the songs in Collapse Into Now (2011), every one of them by a different directos, many of whom came from the contemporary art medium. Between them are stars of the medium like Sophia Calle, from Fance; Lance Bangs, who has directed videos for Nirvana, Arcade Fire, Belle \& Sebastian, among others; Sam Taylor-Wood, director and photographer in the artistic field; Dominic De Joseph, who has been Lance Bangs co-producer, besides previously working for R.E.M. as well; among other directors.

Beyond the confluence between artistic and commercial environments, the whole of the panoramic view on the origins and influences of the music video presented thus far leads us to a discussion about the language of the music video. The conceptual project of music videos for each track in R.E.M.'s album is only one of the many applications of the format which show us the multiple possible configurations of the music video.

From the analysis of only one band, it is also possible to notice the general versatility of the music video production process, appropriating various techniques (animation, image overlapping, ellaborate edition, collage, etc), genres (documentary, drama, fantasy, romance, thrillers, action, among others) and artistic manifestations, from moving 
images to painting, literature and fine arts to compose an essentially hybrid scene. As an example, there are a few animated music videos we can cite, such as the stop motion for The White Stripes's Fell In Love With a Girl (Michel Gondry, 2002), or the more traditional, but nonetheless unusual animation in Portishead's The Rip (Nick Uff, 2008), as is the case of the video for Do the Evolution (Kevin Altieri and Todd McFarlane, 1998), by Pearl Jam, among others. Despite all of them being animated films, we are still able to see how the styles and creative processes behind each one are different. In other videos, it is possible to detect references to other media sources. In the case of Bad Day, (Tim Hope, 2006) by R.E.M., there is a clear reference to telejournalism: the actors in the video sing the song as if they are either presenting or being interviewed by the news program. Lastly, there is the music video for Praise You (Spike Jonze, 1999), by Fatboy Slim, which is a recorded performance by a dance crew in the entrance hall of a cinema.

The examples mentioned above confirm the idea of the inexistence of a fixed delineated language for the music video. For Soares (2012: 16) the music video may fall within "three concepts: hybridism, transtemporality and neobaroque". Hybridism because of its approximation between cinema, television and advertising rhetoric, resulting in a non-specific language. The aspect of transtemporality would be due to its capacity to cover the most diverse sort of references, regardless of their historical hierarchy, resulting in a recurring negotiation between past and present. Canclicini (1997: s.p.) complements this idea by saying the music video "is the most intrinsecally post-modern genre. Intergenre: a mixture of music, image and text. Transtemporal: it gathers melodies and images from various periods, carelessly puts facts out of context; it is a return to Magritte and Duchamp, but for massive audiences". Finally, neobaroque, because,

by uniting avant-garde montage tools, graphic cinema, video art and typically surrealist elements, it is clear that the music video shows us the desire for a kind of aesthetics which are founded in the extasy of superficiality, bringing us back to a sort of culture centered around debris, ruin and waste, a proposal (...) of pleasure through series, through repetition, through the taste of what is serial and known. More of the same things. (...) The music video is located within what Calabrese ${ }^{2}$ himself pinpoints as neobaroque pleasures, thus evoking the dynamics of fixation, a desire for completion, when all the videos can offer is the incomplete, the cut, the tear (Soares, 2012: 52, freely translated).

All of these aspects are evoked in order to define the music video and its multiple, multifaceted nature, and through them Soares (2012) defends the idea that the music video would be a good example in the comprehension of post-modernism. From another perspective, Machado (2007) also explores this premise, although establishing connections strictly between the language of the music video and contemporaneity. According to the author, the structural complexity of the music video is a demonstration

${ }^{2}$ Calabrese, O. (1987) A idade neobarroca. Lisboa: Edições 70. 
of contemporary complexity itself. Even though video is but one of the layers among the many which constitute the music video (as previously said about video art), it is a source whose legacy is mainly the malleability of electronic images.

\section{WHAT IS INTERACTIVE ABOUT THE MUSIC VIDEO}

This debate enables us to introduce in a more direct way the discussion about interactive music videos. On the one hand, in the moment in which video art arose in the 6os, the possibility of manipulating the light spectrum from the cathode ray tube, along easier access to recording equipment, made television (in its analogic version) and the videographic apparatus into experimentation objects which left a strong aesthetic legacy for the music video; on the other hand, nowadays, the internet's technical and technological developments participate as another layer in the genre's juxtaposition of references, and they have a direct reflex on the music video's format and distribution. This process is a part of what Krauss (1999: 12) points at as the post-medium condition, in which it is no longer possible to find a specificity in media and this lack of specificity is what should be explored by art through its developments, such as the confluence of media, languages and artistic values. Such an argument is, by itself, in dialog with the nature of video taken by the author as the responsible for shattering the very idea of media specificity (Krauss, 1999: 24) - and, consequently, the nature of the music video itself. Still on the importance of video, Krauss stresses how the advent of portapak - a light, cheap gadget with a monitor to make videos - resulted in a new demand for the production of narratives (Krauss, 1999: 24), just like the popularization of computers with fast internet connections also created a tension in traditional narrative modes.

The decline of MTV, as a network strictly dedicated to broadcasting music videos, demonstrates the change internet brought to this format. In the introduction for the book "Medium Cool - Music videos from soundies to cellphones", Beebe (2007) pinpoints a few transition moments in MTV's content grid, as the network was created mainly with the objective of propagating music videos, and currently makes larger investments in entertainment programs like reality shows, series, and others, which are not based around music videos. However, these changes reflect a transformation in the habit of the audience, who found in the internet a more pliable vehicle for watching and consuming audiovisual products. Although MTV, specifically, was a pioneer and succeeded greatly (as we can see from its world level expansion and its importance in constructing pop culture) until the development of the internet, as that of its technical attributes, pressured the network into its transformation, to the point where the "Music" in [M]usic [T]ele[V] ision lost its force in the network's programming schedule.

The rise of the music video on the internet and its resulting decadence in TV is only one of the contributing factors for the appearance of its interactive version, which is already becoming worn out by the excessive use of the term "interactivity". For some authors, such as Machado (2007), Paul (2000), Murray (1998) and Primo e Cassol (1999), among others, the term has become trivial due to its unrestricted use for any activity 
linked to an electronic apparatus, from a simple mouse click for switching pages in a navigator to pressing a button on a remote control. Murray (1998), reinforces that "because of the vague and pervasive use of the term interactivity, the pleasure of agency ${ }^{3}$ in electronic environments is often confused with the mere ability to move a joystick or click on a mouse" (Murray, 2003: 128). Specifically in the case of interactive music videos, various levels of agency are noticeable even within the scope of these authors's critiques.

What is vital to stress, above all and in spite of criticism, is the expressive way in which the effort to create digital narratives has been explored since the advent of informatics, be it through music videos, games, or interactive cinema. Although the great majority of the current narratives of cyberspace are marked by simple structures of choice and ramifications, they are valuable as a new potential for narratives, which arises enabling the creation of increasingly creative examples. Moreover, it is remarkable that this effort represents change in the our habit of relating with the stories - such as the emergence of film or video had once been. Therefore, this aspect proves to be most relevant when it comes to the interactivity of music videos: the fact that it brings transformation to the music video format and also determines broader changes in the habit of seeing and creating narratives in a digital environment.

\section{DigITAL NARRATIVES: A NEW WAY OF TELLING STORIES}

In 2004, the canadian rock band Arcade Fire launched their career with their debut studio album, Funeral, followed by Neon Bible (2007), The Suburbs (2010) and, finally, Reflektor in 2013. A recurring feature in the group's work is the release of conceptual albums which contain and represent a theme. For example, upon the release of their latest album, band member Win Butler, in an interview for Rolling Stone (2013), gave some of the references for the creation of Reflektor: mainly haitian and jamaican music and, as a theme, the essay The present age (1846) by philosopher and theologist Kierkegaard. Nonetheless, the band's work project is not limited to their songs. Since their second album, the group has invested in interactive audiovisual productions, from short films to an installation during their concert at the Coachella music festival in 2011 , both of which dialogued with the themes of the albums.

By taking Arcade Fire's interactive music videos as a study object, it becomes clear that their structures differ from that in which the spectator presses play (on the internet) to watch the videos or catches them in a program (on TV). It is assumed that, in the case of interactive music videos, the spectator is an important element for the construction of the final product. Therefore, in this new format, the video takes on multiple aspects, largely playing with the appeal of technological experimenting, which in Arcade Fire's productions has been working as a sample for the development of new programmings supported by Google's creative laboratory. At the same time, however, this does not cause the elimination of music videos which are still within the traditional form, even for

${ }^{3}$ Murray (1998: 127) defines agency as "the satisfying power to take meaningful action and see the results of our decisions and choices" 
Arcade Fire themselves. What happens, in this context, is a process of complexification and imbrication of the narrative forms.

Going beyond Arcade Fire's isolated case, the way in which these sorts of narratives have gained representation, especially in the field of Virtual Arts ${ }^{4}$, is also of notice. Gauldreault (2009) defines narrative as a material object with beggining and end (although there are different ways to tell a story), discourse and happening and proposes that there is no gap between the narrative as discourse and the reader's perception of it. For him, a cinematographic narrative is the one where enunciations are suggested through its images (and the combination must bear a general sense as a unit, which should show logical relations when analyzed as a whole). Although this concept comes from the cinematographic universe, it can be thought in relation and applied to new forms of media, in addition to what Murray states about the author of digital narratives as the one with the role of "a coreographer who supplies the rhythms, the contexts and the set of steps that will be performed" (1998: 153).

Specifically on the narrative directly seen through music videos, Sedeño (2007)

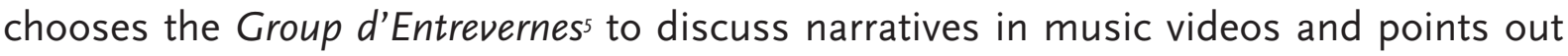
the anti-narrative nature of this video format, as opposed to the rigid structures of classic cinema. Further along, she presents this nature as a result of the junction of three distinct temporalities: music, image and text. Though the three of them cross through each other in music videos, they are not always in congruence and, thus, take on different time frames in the same space; resulting in a fragmentary, discontinuous and shifting perception (Sedeño, 2007: s/p). The author adds that while "classic cinema bases its temporal development in the narrative articulation of scenes which come together to create sequences with chapters as temporal units, defined and distinguished by minimal time elipses" (freely translated), music videos enable the use of any of the three temporalities and invests in the intensification of visual stimuli, which causes a rupture in the cohesiveness of the narrative unit.

For Manovich (2001: 227), an interactive narrative "(which can also be called a hypernarrative in an analogy with the hypertext) can then be understood as the sum of multiple trajectories through a database.". Further on, Manovich criticizes the use of the term narrative referring to any work in new media which uses a database, as arbitrary bits of information acquired from this whole would not result in a series of connected events. Gosciola (20013: 116), on the other hand, in relation to cinematographic narratives, turns to Sergei Eisenstein seeking a demonstation of how film-makers "have used discontinuous narratives to awaken the spectator's critical sense of reality". He goes on, stating that

\footnotetext{
4 The term "Virtual art" is defended by Paul Hertz in "Art, code, and the engine of change" (2009). According to the author, the term is more adequate because it comprehends a wide amount of artistic manifestations in the universe of arts and new media.

5 Definition of the Group d'Entrevernes by the author: "According to this group of semiotic specialists, the analysis of the narrative component is the study of the succession of states and changes which characterize the subject and the object in discourse and the roles they assume in the actions of change. It is said that narrative exists with a narrative program. The narrative program is the sequence of states and changes which are tied over the relationship between subject and object (these characters and whatnot are paper-made, notions that define consecutive positions), that is, the number of steps or changes from a condition (relationship between subject and object) to the other." (Sedeño, 2007: s.p., freely translated)
} 
narratives by way of deconstruction were a resource to find the most expressive manners of the cinematographic medium, exploring all commonly known resources in addition to the discontinuity promoted by the insertion of events, takes and sounds which would break off the logical and chronological sequence of the story (Gosciola, 2003: 116, freely translated).

While in cinema the narrative discontinuity resource is utilized by the assembly to create a greater sense of reality in the viewer, in digital storytelling, it appears almost as a premise of the support itself, in case the computer - but it is nevertheless aside the issues that this discussion adds to the cinematic debate. As is clear in the book "Hamlet on the Holodeck: The Future of Narrative in Cyberspace" Janet Murray (1998), that either this is a recent discussion, mainly because it is a recurring concern in the video game universe and currently of digital games.

Regardless of levels of complexity, from the hardware or the technological apparatus, the narrative forms playing with the discontinuity are usually linked to the "hypertext". In a reference to the works of literature that are written hipertextualmente, Murray suggests that although "is not new as a format for reflection and experience of organization, it was only with the development of computers that hypertext writing was produced on a large scale" (Murray, 1998: 65). Thinking beyond the written text but also in writing programming code, is due to the wide application possible by the computational system that is permanent the resumption of old reflections on the term "hypertext" to strengthen the understanding of digital narrative and its implications.

Firstly utilized by Vannevar Bush in his article As We May Think (1945), and discussed by Lévy in his book "Les technologies d'intelligence" (2004: 16), the concept of hypertext is recurrently recovered to approach narratives that present discontinuity propositions. According to Levy, Bush's concept is inspired in the behavior of human mind, which functions mainly through associations and not through a hierarchic organization. Therefore, it is coherent to reflect on the nature of digital narratives through this concept, once the aprehension of their intrinsic features reinforces their flexibility, if compared to the stiff structures of the great majority of narratives. The author defends that

(...) the structure of the hypertext does not refer only to communications.

The sociotechnical processes, especially, also have a hypertextual form, as do various other phenomena. The hypertext is, perhaps, a metaphor that is valid for all spheres of reality in which significations are at stake (Lévy, 2004: 15, freely translated).

By presenting this argument, Lévy takes the discussion to a wider context, which allows us to think of the idea of the hypertext as the representation for a certain possibility to escape the utopia of organizing thought through rigid structures. In that way, if a concept may be used to describe cognition, then it may also reflect all that comes from it, including artistic productions themselves, whether they belong in the literary, visual or musical field. 
Lévy took the idea of "rhizome", established by Deleuze and Guattari (1995) in the first volume of "A Thousand Plateaus: Capitalism and Schizophrenia", as a base for his description of the hypertext. Deleuze and Guattari (1995) define that

\begin{abstract}
the rhizome connects any point to any other point, and its traits are not necessarily linked to traits of the same nature; it brings into play very different regimes of signs, and even nonsign states. (...) It has neither beginning nor end, but always a middle from which it grows and which it overspills. (...) The rhizome is antigenealogy. It is a short term memory or an antimemory. The rhizome proceeds by variation, expansion, conquest, capture, sting (Deleuze \& Guattari, 1995: 32, freely translated).
\end{abstract}

The concept of the rhizome, then, seems enriching when discussing the hypertext and digital narratives. Murray (1998), by articulating the two ideas, elicits what she calls "digital labyrinths" as coming from "poststructuralist literary theory and are unheroic and solutionless. Like a set of index cards that have been scattered on the floor and then connected with multiple segments of tangled twine, they offer no end point and no way out." (Murray, 1998: 132). Therefore, this would be a possible light to shed on the potentiality and the way with which narratives present themselves on the internet, although, according to criticism from Murray herself, in this undetermined structure of hypertextual narratives there is frustration in the desire for narrative agency, once the actions of subjects only follow a flow of significant choices, without these necessarily entailing a causal relation within a narrative system.

By taking the features of the hypertext, as described by Lévy (2004) and associating them to the digital narratives, it is possible to perceive there is not merely one force, but multiple ones which cross each other, collide and confront each other in a synergy brought on by countless and ever-changing affective and technical processes. Thus, there is not a single way to present or perceive a certain intention; in this context time, space and subject (here, these are ulterior elements) are themselves importat components to be considered for constructing narratives.

On this confluence, and more specifically about the relationship between man and machine, Couchot (2003) points at the existence of a productive relationship when both are at work together. However, for this to be possible, what is corporal and gestural must be recoded into a numerical language, as stated by the author:

All of these trades happen between multiple entry or exit interfaces, and the linkage takes the form of a ring, under computational control. In this way, it is not the corporal being who interacts with the machine, but a sort of numerical "emanation", in linguistic and programatic consequence, comes from it. The observer, too, has partially unfolded into a set of data. It turned them into a simulation. It is only at this cost that a dialogue between man and machine may be established, as well as a conversation between two species of foreign languages which are but "comprehended" - which only 
produce effects - because they are translated by the computer into a common language (Couchot, 2003: 171, freely translated).

Through this approach, there is a clearer perception of how subjects establish this relationship between their gestures and machines, bringing into the discussion a more solid dimension of what is interactivity in a digital environment and how it entwines both human and machine conditions. The common translation of two different languages is powerful, mainly due to what Murray (1998) sees as an "opportunity to enact stories rather than to merely witness them" (Murray, 1998: 170). While participants in the encounter and translation of languages, we experience transforming power once we assimilate these actions as personal experiences.

\section{ARCADE Fire AND THEIR TRAJECTORY IN THE PRODUCTION OF INTERACTIVE MUSIC VIDEOS}

Taking all of the previously mentioned aspects into account and emphasizing narratives in the digital context, I shall return to the starting point of my argumentation about canadian group Arcade Fire, inserted in the internet scenario from its very beginning. Among the resulting works from their albums, I would like to highlight the production of four interactive music videos since the beggining of the band in 2004; the first one was for the song Neon Bible (Vincent Morisset, 2007), the second for Sprawl II (Vincent Morisset, 2010), the third for The Wilderness Downton (Chris Milk, 2010) and the fourth and final, Just a Reflektor (Vincent Morisset, 2013).

The result of a hybridization between cinema and video, the language of music videos carries a narrative load which begins with text/song and is recoded according to a visuality produced by its creators. Particularly in the work of Arcade Fire, their music videos present some of the alternatives discussed by Peter Greenway (2003) in his argumentation on the "end of cinema" controversy, upon the rise of new technologies. Greenaway is the author of hard criticism to the sort of cinema which operates as mere copy and transfiguration from the written word. For him, "cinema should not be an annexe of the library, serving, illustrating literature" (Greenaway, 2003: s.p.). Further into his text he adds, as an alternative "to the current circumstances of the dying technologyaesthetics called cinema, propelled by the need to accept the novelty of interactivity and the revitalized possibilities of multimedia, (...) we will be free from the tyrannies of text, frame, author and camera" (Greenaway, 2003: s.p.). While, on one hand, Greenaway (2003) directs his criticism to a cinema which is strongly connected to text, Machado (2000), on the other hand, sees in music videos a tendency for the reinvention and transgression of audiovisual. However, for him this happens only when "bands assume an independent or suspicious attitude towards the demands of phonographic and television industries (...), or naturally incorporate distortion, dissonant noise and sounds which are unlikely bearable by traditional ears" (Machado, 2000: 178). For Machado, some of the features and tendencies permeating music videos which assume an innovative posture are, for instance, discontinuity and experimentation. Both of them can be observed in the work of Arcade Fire, which despite having explored different themes for 
each album, has made videos, each following their own narratives without corresponding to a literal translation of the song lyrics, bringing, thus, multiple temporalities into their music videos.

As it gained strength on the internet, the music video has assumed new looks which are, still, in dialogue with audiovisual, but also expanding to embrace new artistic forms, for instance, virtual art. This encounter promotes a confluence of creative energies and, in Arcade Fire's case, has Aaron Koblin, the artist of new media, as an important piece in this interaction. He has contributed in the conception of the band's last two videos through partnerships with directors Vincent Morisset and Chris Milk, promoting the tie between audiovisual and visual arts.

More specifically on the context of overlaying different media, in the beggining of the book "Into the Universe of Technical Images", Flusser (2008) indicates the symptoms of what he defines as a "cultural revolution" in which

Photographs, films, TV images, video images and images from computer terminals assume the role of information carriers, earlier played by linear texts. We no longer live, know and valorize the world because of written lines, but now because of imagined surfaces (Flusser, 2008: 15, freely translated).

However, Flusser (2008) further on assumes a critical posture towards the overabundance of technical images in current society (pointing at a dazzling which has as its consequence a disperse individual, distracted and unconscious; or still, the loss of a sense of what is public, due to the individualized manner with which subjects deal with technological objects, which would lead the society to become an amorphous mass - in general, the author talks of a society who denies depth and goes directly towards superficiality). It is perceivable, in the case of music videos, that the explosion of images as a certain way to "produce knowledge" about lyrics and/or song integrates the rhythm of image production for TV, cinema and, now, computers. Surely, we can think of these multiple relations between images and the information their produce as a metaphor for the hypertext, due to the associations between them, their variations according to context or, still, due to the lach of a strict organization for the whole of it. Bringing the same thought towards a reflection about interactive music videos, we can say this logic has repercussions in the way in which the production of these videos imagines and enables narratives, creates their developments and disarticulates them from canonic structures. Videos which, also in the case of Arcade Fire's productions, are enriched by countless resulting products, such as making of videos, parallel sites for the experimentation of their techniques, the production of images or messages from the video to be shared on the web, hyperlinks, among others that continue to expend the amount of information related to the product.

Beyond thinking what these changes in the music video format mean, it is necessary to point to the way society assimilates these new forms and in which this "cultural revolution", little by little, reprograms our habit to view such images. The constant 
reprogramming of the way we view technica images is not recent. In the introduction for the book "The Secret Language of Film", Carrière (1995) tells that after the end of the first great war, French colonial administrators used to organize film screenings in Africa, and important african personalities and religious leaders were invited. As it was impossible to refuse the invitation, people went to the screenings and kept their eyes shut at all times during the movie. Jean-Claude Carrière (1995) reflects on this:

Sometimes I think we, too, are not so different from the muslims in Africa, when we watch a film. Unlike them, we keep our eyes open in the dark, or at least we think we do. But are we not harbouring, deep within ourselves, some sort of taboo, or habit, or incapacity, or obsession, which stops us from seeing the whole or a part of the video which fleetingly glows before us? (Carrière, 1995: 10, freely translated).

There are, then, opposing forces: on one hand the language transformations and on the other resistance by habit. In this way, there is a dialectic between these two forces which has been synthesized with every new transgression in the music video format and which translates into gradual changes on the way to view. The very success in the distribution of music videos on the internet, its adaptation to the virtual space and, consequently, the changes in strategy from MTV's part, show us these changes surpass the discussions on language and reach sociotechnical questions on the ambit of "viewing", going through the update of a certain habit caused by the constant renovation and growing popularization of new technologies.

Still on this transformation of the viewin habit, the book "Technologie dans l'art", by Couchot (2003) brings into view a difference in relation to images that were previously dominant in cinema and TV before the rise of computers, but this time under the optics of image production. The author states that, in the digital context, images have a representative difference if compared to yore. While in analogic capturing the result is the trace of something that really happened, in the universe of digital images, what we have are small dots, formed through algorithms and used to compose the final product. For Couchot (2003), digital images have a different time in which there is a synthesis of the very relationship between work and spectator.

Uchronical time does not replace "what was", referring to the past, nor "what is", resending it to a perpetual present, but a "this could be", open to countless eventualities. The temporal modality of virtual worlds is eventuality. It is a result of the interface which establishes itself between the time of the observer, the one lived by him at the moment he sees the image, and the time of the image at the moment it is engendered by calculus (Couchot, 2003: 169, freely translated).

Therefore, the changes in the way images are captured, generated and processed are in direct dialogue with the way we perceive them and with the rupture in the habit to view things as the truth, as an indicative of a past happening. In all interactive videos by 
Arcade Fire, simulation and image manipulation artifices are used, in such a way the very bond between video and spectator happens through the possibility of interfering and playing with time on the screen, in the song and in the narrative.

All of the explored aspects lead us to the evidence of an overlapping of techniques and languages, which has gained strength in the production of music videos, specially interactive ones. Manovich (2004) argues that, "This proliferation of hybrid images leads us to another effect - the liberation of the techniques of a particular medium from its material — and toolspecificity." (Manovich, 2004:341). Therefore, it is no longer possible to fit these audiovisual productions into a determined type of language, as well as its own specificity; rather than that, there is a confluence of codes originated in the most diverse areas such as cinema, video and digital production. If we take Arcade Fire's interactive video production as a general panorama, it becomes clearer. And if we take a single example like the video for The Wilderness Downton (Chris Milk, 2010) in which we can see how cinematographic language dialogues with the production of graphic effects, and that is still related to digital programming, this hybridization becomes even more evident.

It may be through this confluence that digital narratives gain strength and space to transform themselves. In this context, the music video appears as a space of experimentation which benefits greatly from the way it has been quickly and easily assimilated in the virtual environment. Which explains, thus, the relatively advanced way in which the reflections on its format resulted in changes in its configuration.

\section{REFERENCES}

Beebe, R. \& Middleton, J. (eds.) (2007) Medium Cool - Music from Soundies to Cellphones, Durham \& London: Duke University Press.

Canclini, N. G. (1997) "Culturas Híbridas - estratégias para entrar e sair da modernidade”, in Canclini, N. G. (1997) Culturas híbridas, poderes oblíquos, São Paulo: EDUSP, pp. 283-350, available at http://www.ufrgs. br/cdrom/Garcia/garcia.pdf, accessed on 03/01/2014.

Carrière, J. (1995) A linguagem Secreta do Cinema, Rio de Janeiro: Nova Fronteira.

Cortázar, J. (1968) O Jogo da Amarelinha, São Paulo: Círculo do livro.

Couchot, E. (2003) A Tecnologia na Arte - Da Fotografia à Realidade Virtual, Porto Alegre: Ed. UFRGS.

Cuevas, F. J. P. (2013) This Is Not a Love Song: Cruce de Caminos entre Videocreación y Música Pop, Barcelona: [La virreina].

Deleuze, G., Guattari, F. (1995) Mil Platôs - Capitalismo e Esquisofrenia, vol. 1, Rio de Janeiro: Ed. 34, 1995, available at http://www.ileel.ufu.br/lep/arquivos/textos_geral/Mil_Platos_1.pdf, accessed on $12 / 12 / 2013$.

Doyle, P. (2013) “Win Butler reveals secret influences behind Arcade Fire's 'Reflektor'”, Rolling Stone, s/p, 22/12/13, available at http://www.rollingstone.com/music/news/win-butler-reveals-secret-influencesbehind-arcade-fires-reflektor-20131022\#ixzz2nr6pHmy2, accessed on 10/12/2013.

Flusser, V. (2008) O Universo das Imagens Técnicas - Elogio da Superficialidade, São Paulo: Annablume. 
Gaudreault, A. (2009) A Narrativa Cinematográfica, Brasília: Editora Universidade de Brasília.

Gosciola, V. (2003) Roteiro para as Novas Mídias - Do Cinema às Mídias Interativas, São Paulo: Editora Senac.

Goodwin, A. (1992) Dancing in the Distraction Factory - Music Television and Popular Culture, Minneapolis: Universityof Minnesota Press.

Greenaway, P. (2007) "O cinema está morto, vida longa ao cinema", Caderno SESC Videobrasil - (3) 3: 88-103.

Hertz, P. (2009) "Art, code, and the engine of change", Art Journal, 68 (1): pp. 59 - 75, available at http:// xarts.usfca.edu/ rbegenhoefer/DigLitog/reading1.pdf, accessed on 10/12/2013

Krauss, R. (1999) A Voyage on the North Sea - Art in the Age of the Post-Medium Condition, Londres: Thames \& Hudson.

Lévy, P. (2004) As Tecnologias da Inteligência, Costa, São Paulo: Editora 34, $13^{\text {a }}$ ed.

Lima, T. (2011) "Michael Jackson e o thriller das gravadoras: trajetória e crise de um modelo", in Janotti Jr, J. S., Lima, T. R., Pires, V. de A. N. (orgs) (2011) Dez Anos a Mil: Mídia e Música Popular Massiva em Tempos de Internet, Porto Alegre: Simplíssimo, pp 35-52.

Machado, A. (2000) "Reinvenção do videoclipe", in Machado, A. (2000), A TV Levada a Sério, São Paulo: Editora SENAC, pp. 173-186

Machado, A. (2007) “Pós-cinema: Ensaios sobre a modernidade”, in Machado, A. (2007) Pré-Cinemas Q PósCinemas, Campinas: Papirus, pp. 172-262

Manovich, L. (2004) Abstraction and complexity, pp. 339-354, available at http://www.mediaarthistory.org/ refresh/Programmatic\%2okey\%20texts/pdfs/manovich.pdf accessed on 01/09/2013

Manovich, L. (2001) The Language of New Media, London: MIT Press, available at www.manovich.net/LNM/ Manovich.pdf, accessed on 15/07/2014

Murray, J. H. (1998) Hamlet on the Holodeck: The Future of Narrative in Cyberspace. Cambridge, US-MA: The MIT Press, 1998.

Paul, C. (2003) Digital Art - World of Art, London: Thames and Hudson. 2003.

Primo, A. F. T. \& Cassol, M. B. F. (1999) “Explorando o conceito de interatividade: definições e taxonomias", Revista do Programa de pós-graduação em Informática na Educação: teoria a prática, Rio Grande do Sul, 2 (2): 65-8o, available at http://seer.ufrgs.br/index.php/InfEducTeoriaPratica/article/view/6286/3756 accessed on $12 / 03 / 2014$

Señedo, A. M. (2007) "Narración y descripción en el videoclip musical”, Revista eletrônica Razón y Palabra, (56), n.p, available at http://www.razonypalabra.org.mx/anteriores/n56/asedeno.html accessed on $10 / 09 / 2014$

Soares, T. (2012) Videoclipe: O Elogio da Desarmonia, João Pessoa: Marca de Fantasia.

\section{MUSIC VIDEO REFERENCES}

Fire, A. (2007) Neon Bible, Montreal: Vincent Morisset

Fire, A. (2010) Sprawl II (Mountains beyond monutains), Montreal: Vincent Morisset 
Fire, A. (2010) We used to wait, Califórnia: Chris Milk

Fire, A. (2013) Just a reflektor, Montreal: Vincent Morisset

Jam, P. (1998) Do the evolution, Kevin Altieri e Todd McFarlane.

Portishead (2008) The Rip, Nick Uff.

R.E.M. (2006) Bad Day, Tim Hope.

Slim, F. (1999) Praise You, Califórnia: Spike Jonze.

Stripes, T. W. (2002) Fell in Love with a girl, Michel Gondry.

\section{BIO NOTE}

Elisa Maria Rodrigues Barbosa was born in 1989, graduated in Social Communication at PUC Minas and works as a researcher at the Institute of Arts and Design at the Federal University of Juiz de Fora - her main interests are the digital storytelling and virtual art. She is currently teaching the course "Games as a teaching resource: propositions in art and technology" at the school Oi Kabum!, in Minas Gerais, Brazil.

E-mail: elisa.mariarb@gmail.com

Universidade Federal de Juiz de Fora, Instituto de Artes e Design, Campus Universitário, Martelos, Juiz de Fora, Minas Gerais, 36036-330 - Brazil

* Submitted: 30-11-2014

* Accepted:15-3-2015 